\title{
Pequena contribuição à História Natural de alguns Fringillidae do Brasil (Passeriformes)
}

\author{
LUIZ GONZAGA E. LORDELLO
}

(Assistente da Cadeira de Zoologia da Escola Superior de Agricultura "Luiz de Queiroz" da Universidade de S. Paulo)

\section{INDICE}

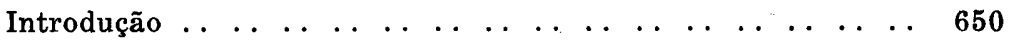

1 - Oryzoborus angolensis angolensis (Linnaeus) (Carduelinae) 651

2 - Oryzoborus crassirostris maximiliani Cabanis (Carduelinae) 659

3 - Cyanocompsa cyanea sterea Oberholser (Richmondeninae) $\mathbf{6 6 0}$

4 - Coryphospingus cucullatus rubescens (Swainson) Emberizinae) 660

Summary . . . . . . . . . . . . . . . . . . . . . . . . . . . . 6660

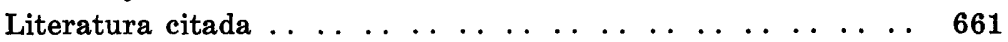




\section{INTRODUÇAOO}

Escrevemos em trabalho anterior (1950) que a reprodução de aves selvagens em condições de cativeiro não é coisa muito fácil. Se isto é verdade para tôdas as espécies da Ornis do Brasil, ainda maiores são as dificuldades quando se tratar de reproduzir Passeriformes.

Daí a razão das contribuições que têm aparecido sôbre êste assunto, referirem-se, em maior escala, a espécies de outras ordens, que não a dos Passeriformes. Faz exceção o canário da terra - Sicalis flaveola brasiliensis (Gmelin) - Fringilídeo cuja reprodução em viveiros constitui mesmo banalidade.

De alegre presença ao redor das instalações das fazendas paulistas, o canário da terra se aproxima bastante do homem, não raro nidificando nos beirais das habitações. Em cativeiro, adapta-se perfeitamente e com facilidade reproduz-se.

Sôbre esta espécie, são interessantes as observações de BRITO (1950).

As tentativas de reprodução em cativeiro de Anatídeos coroaram-se de pleno êxito para com Cairina moschata (Linnaeus), que deu origem ao pato doméstico, de importância não pequena em Avicultura, e para a elegante marreca irerê Dendrocygna viduata (Linnaeus) - que, segundo nos consta, também se aproxima da domesticação, uma vez que tende a satisfazer os principais requisitos exigidos para tal, tão bem expressos no trabalho de TORRES (1947).

Por outro lado, a observação dos costumes e reprodução das espécies in natura exige a permanência prolongada do observador no local onde elas ocorrem, o que nem sempre é realizável. Não é por outro motivo que SPIX, NATTERER, WIED e tantos mais, grandes naturalistas do passado, que percorreram o continente americano, muito pouco contribuiram para isso, quando tão elevadas foram as suas produções no campo da Taxonomia Ornitológica. Aliás, a Ornitologia Brasileira teve, dessa forma, a marcha normal de evolução de qualquer ramo das Ciências Biológicas. As investigações sistemáticas, sendo fundamentais, devem ser levadas a cabo em primeiro plano.

Com isso, se o estudo taxonômico das Aves do Brasil quase nada deixa a desejar, muitas ainda são as falhas existentes no capítulo do conhecimento de seus costumes e modos de reproducãn. 
Foi considerando isso tudo que nos animamos a dar publicidade às pequenas observações que constituem estas notas, incluindo dados sôbre a reprodução de algumas espécies de Fringillidae em condições de cativeiro, que embora bastante artificiais, dão uma idéia do comportamento das mesmas na natureza.

Iniciando, não podemos deixar de agradecer ao eminente naturalista Dr. Olivério $M$. de Oliveira Pinto, Diretor e Chefe da Divisão de Aves do Departamento de Zoologia de S. Paulo, por ter-nos permitido o estudo dos exemplares de Oryzoborus angolensis da coleção a seu cargo, espécie principalmente tratada nestas notas.

Também somos gratos ao nosso prezado amigo Durval de Moraes Salles, arguto observador, por ter-nos registrado dados sôbre a reprodução de espécies aqui referidas.

Ao Professor Dr. Walter Radamés Accorsi, Catedrático de Botânica da Escola "Luiz de Queiroz", os nossos agradecimentos pela identificação de plantas.

\section{1 - Oryzoborus angolensis angolensis (Linnaeus) (Carduelinae)}

\section{NOMES VULGARES}

IHERING \& IHERING (1907) registram para O. angolensis os nomes populares "avinhado" e "curió", o último dos quais OLIVEIRA PINTO (1940) reserva para o Nordeste do Brasil, desde a Bahia.

As mesmas denominações são empregadas no Estado de $\mathbf{S}$. Paulo, sendo, com efeito, o têrmo "avinhado" de uso francamente dominante.

Na região de Piracicaba, onde a espécie foi outrora abundante, "curió" é a única apelação utilizada, constituindo, assim, uma exceção dentro do Estado de São Paulo.

O mesmo nome é usado na Argentina, conjuntamente com "arrocero", para designar a mesma espécie, consoante a Lista Sistemática das aves daquele País, organizada pela Secção Ornitológica do Museu de Ciências Naturais (1941).

Para a subespécie amazônica, são registradas por OLIVEIRA PINTO (1944) as apelações "peito-roxo", "curió" e "papaarroz", esta última também mencionada por VIEIRA (1936) e GYLDENSTOLPE (1945) e, sem dúvida, alusiva à estima que 
o pássaro devota às cariopses dêsse cereal, máxime áquelas ainda verdoengas.

\section{NOTAS BIOLOGICAS}

Não sendo muito abundante em parte alguma, o "curió" existe espalhado por quase todo o Brasil, afirma o ornitólogo OLIVEIRA PINTO (1935).

$\mathrm{Na}$ época de reprodução, os casais são vistos nos lugares descampados, máxime nas proximidades das correntes ou porções paradas de água, o que sem dúvida é relacionado com o tipo de vegetação aí existente, de cujos frutos a espécie faz a sua alimentação.

Eminentemente granívora, aprecia as cariopses de diversas gramíneas nativas, inclusive, como nos foi dado observar, as da conhecida grama ou capim de Batatais (Paspalum notatum Flügge), de larga distribuição desde o México á Argentina.

Em seu regime alimentar também figuram Ciperáceas. De fato, a espécie aprecia os frutinhos da "navalha de mico" Scleria silvestris N. ab E. - (Ou "navalha de macaco", consoante registram LOEFGREN \& EVERETT, 1905), vegetal bastante conhecido de tantos quantos se dispõem a cruzar certas zonas, graças ás propriedades cortantes de seus colmos e fôlhas, o que lhe valeu as expressivas denominações populares referidas.

Muito embora apareça em terrenos secos, àparentemente em bom estado de desenvolvimento, esta planta parece preferir as margens dos rios e os terrenos alagadiços, onde mais de uma vez a colhemos. A época de frutificação coincide, de um modo geral, com a da atividade reprodutiva do Fringillidae em estudo.

O conhecimento do regime alimentar de uma ave é sempre de interesse para o homem. Endossando a opinião de HEMPEL (1949), isso constitui, também ao nosso ver, a chave do êxito quando se pretende fazê-la reproduzir-se em situações artificiais. Escrevemos há algum tempo (1950) que, tratando de espécies pelo menos parcialmente insetívoras, as larvas do conhecido coleóptero Tenebrio molitor Linnaeus são um poderoso auxiliar e vêm substituir as chamadas "vermineiras" dos europeus, para aproveitamento de larvas de dípteros, que não passam de processos anti-higiênicos.

Chegada a época de reprodução, que se inicia por volta dos meses de Outubro e Novembro, os sexos se procuram e os casais elegem um local para a feitura do ninho, sempre um ar- 
busto, a pouca altura do solo. Macho e fêmea trabalham na feitura do ninho, que aliás não é feito com elevado esmêro. $O$ material empregado é constituido de raízes e colmos finos de capins.

O ninho se enquadra no terceiro tipo da classificação de EULER (1900): cadinho aberto - no qual são depositados dois ovos, assim descritos por IHERING (1900) : medem $19 \times 14 \mathrm{~mm}$., são branco-cinzentos, com manchinhas bruno-cinzentas e alguns pontos e garatujas pretas, que faltam em parte dos ovos.

Três cvos por postura, registrados por SANTOS (1940), parece não corresponder á generalidade. Com efeito, nos oito casos observados, houve apenas dois ovos, concordando assim com as observações de SCHOMBURGK e WIED (citados por EULER, loc. cit.), segundo as quais a maior parte dos nossos pássaros põe de fato apenas dois, embora EULER (loc. cit.) tenha achado tão numerosas exceções que passou a indicar três ovos por postura como sendo o caso geral.

Para conseguir-se a reprodução da espécie, os casais foram colocados em gaiolas de aproximadamente $100 \times 40 \times 60$ (comprimento, largura e altura, em centímetros), em cujo interior colocaram-se galhos finos e ramificados, para servirem de pontos de fixação do ninho a ser construido. Acontece algumas vezes que a fêmea parece não aceitar o local determinado para a construção, tornando-se necessária a sua transferência para outro ponto.

Durante todo o tempo, os dois sexos procuram a água, banhando-se frequentemente.

As cópulas dão-se poucos dias antes da postura, estando o ninho pràticamente construido. $\mathrm{A}$ incubação, realizada ùnicamente pela fêmea, exige cêrca de 13 dias e, durante êsse tempo, o macho não procura alimentá-la; ela tem de abandonar o ninho para nutrir-se.

Nascidos os filhotes, os dois pais cuidam da alimentação, regorgitando para a cavidade oral dos filhos o alimento que ingeriram.

Os jovens exigem o concurso dos pais por cêrca de 40 a 50 dias, findos os quais passam a se alimentar por si próprios.

Durante êsse tempo, os adultos não tratam de nova postura e, como o período de reprodução vai únicamente até fíns de Fevereiro ou Março, não é possível mais que duas criações por ano. Aliás, WIED e BURMEISTER (citados por EULER, loc. cit.) concederam duas posturas anuais como regra geral para os pequenos pássaros do Brasil, não negando a possibilidade de uma terceira. EULER (loc. cit.) admitiu a terceira postura 
como normal para vários gêneros e a segunda como absoluta para a totalidade dos Passeriformes.

FRIEDMANN (1948), verificando a presença de gônadas bem desenvolvidas em dois "curiós" machos coligidos na Venezuela (Rio Orinoco), em Março e Maio de 1931, sugeriu que êsses meses fazem parte do período de atividade reprodutiva da espécie naquela região americana (subespécie $O$. a. torridus (Scopoli)) .

Para o observador prático, muitas vezes desde verdes anos dedicado á observação destas aves canoras, é possível distinguir os sexos dos filhotes de Oryzoborus angolensis, mesmo antes de estarem se alimentando por si próprios. Além de se comportarem diferentemente, os machos jovens são menos encorpados do que as fêmeas. No mais, ainda dentro dêste período em que os jovens recebem alimento dos pais, quando as retrizes ainda não se igualaram em comprimento, os machos emitem os primeiros gorgeios, fazendo denunciar o seu sexo com quase absoluta segurança.

Com respeito ás plumagens que se sucedem até que os machos ganhem o estado de adultos (chamamos de machos adultos áqueles que exibem a plumagem escura característica, que tẩo bem os distingue das fêmeas e jovens, embora antes disso já apresentem o aparelho reprodutor bem formado), devemos đizer que a primeira muda dá-se não muito tempo depois de abandonados pelos pais, permanecendo inteiramente pardos como sairam do ninho. Após a segunda troca, alguns machos já adquirem a plumagem definitiva, mas o geral é adquirirem coloração mista, ou seja, plumagem de adulto e máculas maiores ou menores, localizadas indiferentemente, com a côr característica dos jovens e fêmeas.

Feita a terceira muda de penas, passam a mostrar coloração definitiva.

\section{SÔBRE AS VARIAÇÕES DE PLUMAGEM}

A còloração das fêmeas e machos jovens já é sujeita a variações. Com efeito, a tonalidade pardacenta ora tende para menos ou mais, dando origem a indivíduos bem claros e, outras vezes, de um pardo carregado.

Nos machos, isto é, com a plumagem definitiva, as alterações se traduzem pelo aparecimento no pescoço anterior, de laivos ou fitas marrons, da mesma côr do peito, o que, contudo, não é muito frequente. 
Como já foi notado por HELLMAYR (1938), quanto à parte visível do espêlho das asas, aperecem todos os gráus de extensão em indivíduos de mesma procedência. Há exemplares em que ela se traduz por um vestígio, quando não falta por completo, ao lado de outros onde é bastante extensa.

As variações de coloração tendentes ao albinismo têm sido constatadas, havendo a considerar aqui os dois tipos de fenómenos, a que nos reportamos em nota anterior (1951). E' que temos observado machos de Oryzoborus angolensis com alterações na plumagem, decorrentes de longa permanência em condições de cativeiro. De fato, êsses indivíduos podem aparecer com maculações alvas, às vezes bem extensas.

Por outro lado, os casos de exemplares com manchas brancas coligidos na natureza têm sido igualmente constatados. GYLDENSTOLPE (1945), por exemplo, refere-se a um exemplar procedente de Santo António (Rio Eirú, Amazonas), que possui "some of the feathers on the forehead and on the anterior portion of the crown distinctly tipped with white".

$\mathrm{Na}$ coleção seriada do Departamento de Zoologia aparece também um indivíduo com pequenas máculas albinas próximas à base da mandíbula inferior.

\section{SÔBRE AS RAÇAS GEOGRAFICAS}

LINNAEUS, ao descrever a espécie (Loxia angolensis Linnaeus, 1776), atribuiu-lhe a denominação específica angolensis, por julgar que sua pátria se prendia à região africana de Angola.

HELLMAYR (1906, 1908) esclareceu o assunto e substituiu a localidade típica pelo Este do Brasil.

Presentemente, a Ornitologia admite duas subspécies, sendo que a raça típica se estende pelas partes oriental e meridional do Brasil.

A segunda raça - Oryzoborus angolensis torridus (Scopoli) - limita-se ao Brasil Amazônico.

Conforme já foi dito por HELLMAYR (1938) e GYLDENSTOLPE (1945), a distinção entre elas se baseia ùnicamente nas dimensões. Em tudo o mais elas são uniformes.

Transcrevemos o que, á êste propósito, escreve o último dos autores referidos: “ $O$. a. torridus is distinguished from $O$. a. angolensis (Lin.) of eastern southern Brazil, Argentina, Paraguay and eastern Bolivia by its slightly smaller size (wing 
56-60 mm.; tail $52-57 \mathrm{~mm}$., against $59-64 \mathrm{~mm}$ and $55-62 \mathrm{~mm}$. respectively in $O$. a angolensis). In addition, it has a decidedly smaller and less bulky bill".

Submetendo à mensuração os exemplares de ambas as raças da coleção do Departamento de Zoologia de S. Paulo, organizamos a relação seguinte, na qual se registram também os sexos (m. e f.), as procedências e os coletores, sendo as dimen. sões (asa, cauda e culmen) dadas em milímetros.

\section{Oryzoborus angolensis angolensis (Linnaeus)}

25258, m., Rio doce, baixo Piracicaba, marg. dir., M. Gerais, A. M. Olalla col., set. $1940,59,0 ; 62,0 ; 12,5$.

26083, m., Fazenda Varjão, Lins, S. Paulo, A. M. Olalla col., jan. $1941,59,5 ; 57,0 ; 13,0$.

6272, m., Espírito Santo, Garbe prep., jan. 1906, 58,0; 61,0; 13,0.

9882, m., Vila Olímpio, Garbe prep., nov. 1916, 60,0; 56,0;13,0.

25252, m., Rio Doce, baixo Piracicaba, marg. esq., M. Gerais, A. M. Olalla col., ago. $1940,59,0 ; 59,0 ; 11,5$.

3094, m., Piquete, S. Paulo, J. Zech col., dez. 1896, 61,0; 61,0; 13,0. 30480 , m., Palmeiras, A. M. Olalla col., jun. 1944, 61,0; 59,0; 12,0. 26084, m., Barra do Rio Dourado, S. Paulo, A. M. Olalla col., jan. 1941, 60,5; 59,0;13,0.

24299, m., Fazenda Poço Grande, Rio Juquiá, S. Paulo, A. M. Olalla col., mai. $1940 ; 61,0: 59,0 ; 13,0$.

25256, m., Rio Doce, baixo Piracicaba, marg esq., M. Gerais, A. M. Olalla col., ago. $1940,59,0 ; 59,0 ; 12,0$.

27061, m., Serra da Bocaima, Conf. de Rio e S. Paulo, A. M. Olalla col., ago. 1941, 61,0;59,0;11,0.

31931, m., Porto Marcondes, Rio Paranapanema, E. Dente col., nov. $1946,67,0 ; 68,0 ; 11,5$.

15232, m., Faz. M. Peixoto, Rio das Almas, Oliv. Pinto col., out. $1934,59,0 ; 59,0 ; 13,0$.

25259, m., Faz. Boa Esperança, São José da Lagoa, M. Gerais, A. M. Olalla col., nov. $1940,61,0 ; 65,0 ; 11,5$.

32644, m., Rio das Mortes, Chavantina, M. Grosso, H. Sick col., nov. $1947,60,0 ; 55,0 ; 12,0$.

15283, m., Inhumas, ant. Goiabeiras, J. Lima col., out. 1934, 61,0; 61,$0 ; 11,0$.

15291, m., Inhumas, ant. Goiabeiras, J. Lima col., nov. 1934, 62,$0 ; 56,0 ; 11,0$.

33911, m., Pau Gigante, Espírito Santo, L. C. Ferreira col., fev. $1940,58,0 ; 59,0 ; 12,0$.

3092, m., Iguape, R. Krone col., 1896, 58,5; 60,0; 13,0. 
28130, m., Guaraparí, Espírito Santo, Oliv. Pinto col., out. 1942, 59,$5 ; 57,0 ; 11,0$.

3093, m., São Sebastião, S. Paulo, H. Pinder col., nov. 1896, 60,$0 ; 59,0 ; 13,0$.

24676, m., Pau Gigante, Espírito Santo, E. G. Holt col., nov. $1940,60,0 ; 60,5 ; 13,0$.

33910, m., jov. Paiu Gigante, Espírito Santo, L. C. Ferreira col., fev. $1940,55,5 ; 56,5 ; 10,0$.

30481, m., jov., Palmeiras, M. Grosso, A. M. Olalla col., jun $1944,59,0 ; 52,0 ; 12,0$.

24298, f. ?, Faz. Poço Grande, Rio Juquiá, S. Paulo, Oliv. Pinto col., mai. 1940, 57,0; 53,5; 11,0 .

15281, m., jov., Faz. M. Peixoto, Rio das Almas, Oliv. Pinto col., out. $1934,57,0 ; 55,0 ; 13,0$.

29717, f., Iporanga, S. Paulo, J. Lima col., jan. 1944, 57,5; 57,5; 12,5 .

31708, f., Boracéia, S. Paulo, E. Dente col., jul. 1946, 62,0; 62,0; 13,0 .

29656, m. jov., Ubatuba, S. Paulo, J. Lima col., nov. 1943, 60,0; 58,$0 ; 12,0$.

27062, f., Serra de Caraguatatuba, S. Paulo, A. M. Olalla col., set. $1941,57,0 ; 59,0 ; 13,5$.

23934, f., Faz. Santa Rosa, Parauna, M. Grosso, J. Lima col., mai. $1940,58,5 ; 60,5 ; 11,0$.

25255, m. jov, Rio Doce, baixo Piracicaba, marg. esq., M. Gerais, A. M. Olalla col., ago. $1940,57,5 ; 56,0 ; 12,5$.

33909, f., Pau Gigante, Espírito Santo, R. C. Donald col., nov. $1940,55,5 ; 57,0 ; 12,5$.

8603, f., Iguape, S. Paulo, R. Krone col., sem data, 55,5; 55,5; 14,0 .

34609, m. jov., Rio Itauna, Espírito Santo, E. Dente col., nov. $1950,58,0 ; 55,0 ; 13,5$.

12665, m. jov., Três Lagoas, M. Grosso, J. Lima col., jul. 1931, 61,$0 ; 56,0 ; 12,0$.

26620, f., Faz. Transwall, Rio Verde, Goiás, W. Garbe col., abr. $1940,57,0 ; 54,5 ; 12,0$.

13878, f., Mogí das Cruzes, S. Paulo, J. Lima col., mar. 1933, 61,$0 ; 60,0 ; 12,0$.

33912, f., Ilhéus, Bahia, L. C. Ferreira col., out. 1944, 54,5; 51,0; 13,0 .

14343, f., Rio Congogí, Bahia, Oliv. Pinto col., dez. 1932, 56,0; 56,$0 ; 12,0$.

24690, f., Pau Gigante, Espírito Santo, E. G. Holt col., set. $1940,57,0 ; 55,0 ; 14,0$. 
32645, m. jov., Rio das Mortes, Chavantina, M. Grosso, H. Sick col., jan. 1947, 60,0;57,0;12,0.

23929, m. jov., Faz. Ponte Nova, Macaúbas, J. Lima col., mai. $1940,57,0 ; 55,5 ; 11,0$.

15280, m., Tabatinguera, Cananéa, Camargo col., nov. 1934, 60,$0 ; 56,0 ; 13,0$.

28131, m. jov., Chaves, Santa Leopoldina, Espírito Santo, A. M. Olalla col., ago. $1942,58,0 ; 55,5 ; 12,5$.

25254, m., Rio Doce, baixo Piracicaba, marg. esq., M. Gerais, A. M. Olalla col., set. $1940,61,0 ; 57,0 ; 12,0$.

33913, f., Ilhéus, Bahia, L. C. Ferreira col., out. 1944, 55,5; 54,0; 12,0 .

27459, m. jov., Faz. Japuiba, Angra dos Reis, Rio de Janeiro, J. Lima col., jun. 1941, 59,0; 57,0; 11,5.

15279, f., Inhumas, ant. Goiabeiras, Goiás, J. Lima col., out. $1934,63,0 ; 57,0 ; 12,0$.

25257, m. jov., Rio Doce, baixo Piracicaba, marg. dir., M. Gerais, W. Garbe col., ago. $1940,58,0 ; 55,5 ; 11,0$.

25253, sexo ?, Rio Doce, baixo Piracicaba, marg. esq., M. Gerais, A. M. Olalla col., ago. $1940,60,0 ; 62,0 ; 12,0$.

26085, m., Embura, S. Paulo, A. M. Olalla col., dez. 1940, 62,0; 60,$0 ; 13,0$.

17318, f., Faz. Maravilha, Vila Sto. António, Cuiabá, M. Grosso, J. Lima col., nov. $1937,57,0 ; 55,0 ; 12,0$.

\section{Oryzoborus angolensis torridus (Scopoli)}

19626, m., Rio Juruá, João Pessoa, Amazonas, A. M. Olalla col., out. $1936,60,0 ; 57,0 ; 11,5$.

19623, m., Idem, A. M. Olalla col., jan. 1937, 58,0; 57,5; 12,0 .

19624, m., Idem, A. M. Olalla col., dez. $1936,57,0 ; 54,5 ; 12,0$.

19627, m., Idem, A. M. Olalla col., out. $1936,57,5 ; 58,0 ; 11,0$.

19625, m., Idem, A. M. Olalla col., dez. 1936, 57,0; 53,5; 11,0 .

22994, f., Idem, A. M. Olalla col., fev. $1937,54,0 ; 51,0 ; 12,0$.

23042, m., Idem, A. M. Olalla col., mar. 1937, 57,0; 53,0; 13,0 .

19699, m., Itacoatiara, Rio Amazonas, Amazonas, A. M. Olalla col., mar. $1937,58,0 ; 53,0 ; 12,0$.

17009, m., Manacupurú, Rio Solimões, Amazonas, Camargo col., out. $1936,57,0 ; 52,0 ; 12,0$.

A mensuração dos exemplares da pequena coleção da Cadeira de Zoologia da Escola "Luiz de Queiroz" forneceu os seguintes dados (O. a. angolensis): 
90, m., Piracicaba, S. Paulo, Osw. T. Mendes col., fev. 1951, 60,$0 ; 55,0 ; 13,0$.

167, m., Piracicaba, S. Paulo, Osw. T. Mendes col., jul. 1951, 63,$0 ; 61,0 ; 14,0$.

168, m. jov., Piracicaba, S. Paulo, V. A. Cobra col., dez. 1950, 59,$0 ; 59,0 ; 12,0$.

206, f., Piracicaba, S. Paulo, col. ?, out. 1951, 56,5; 60,0; 12,5 .

211, f., Piracicaba, S. Paulo, col. ?, out. 1951, 55,0; 58,0; 12,5.

Por ai se vê que as dimensões dos machos adultos (os limites de HELLMAYR (loc. cit.) e GYLDENSTOLPE (loc. cit.) referem-se a êstes indivíduos) oscilaram da seguinte forma :

1) O. a. angolensis (Linnaeus). asa......58 a $63 \mathrm{~mm}$ (com um indivíduo de $67 \mathrm{~mm}$. de asa).

cauda....55 a $65 \mathrm{~mm}$. (com o mesmo indivíduo com $68 \mathrm{~mm}$. de cauda).

culmen....11 a $14 \mathrm{~mm}$.

2) O. a. torridus (Scopoli).

asa......57 a $60 \mathrm{~mm}$.

cauda....52 a $58 \mathrm{~mm}$.

culmen....11 a $13 \mathrm{~mm}$.

Pelos limites empregados por HELLMAYR (loc. cit.) e GYLDENSTOLPE (loc. cit.) na caracterização, os casos intermediários ficam insolucionáveis e, no mais, como o próprio HELLMAYR (loc. cit.) reconhece, os indivíduos isolados de $O$. a. torridus são muitas vezes inseparáveis da raça típica.

Dessa forma, deixam muito a desejar as vantagens do reconhecimento da subespécie amazônica, sendo assim tão frágeis os caracteres que a distinguem do "curió" de todo o resto do Brasil.

2 - Oryzoborus crassirostris maximiliani Cabanis (Carduelinae)

O "bicudo", ou "bicudo do norte" como é conhecido na região de Piracicaba, é ave muito menos frequente que a espécie anterior. 
Adapta-se bem às situações artificiais, aceitando o mesmo tipo de alimentação do "curió", podendo viver muitos anos.

Quanto à sua reprodução, obtivemos postura de uma fêmea, com dois ovos, os quais não lograram eclosão, embora a cópula tivesse sido verificada por várias vezes.

Ninho e ovos foram descritos por MONTE (1928), de material coligido em Arcos, no Estado de Minas Gerais.

\section{3 - Cyanocompsa cyanea sterea Oberholser (Richmondeninae)}

O "azulão" ou "bicudo da terra" nidificou e fez posturas em cativeiro. Sôbre os ovos, em número de dois, há as notícias de IHERING (1900).

A incubação exigiu mais ou menos 13 a 15 dias. Em todos os casos observados, os filhotes não lograram desenvolver-se, perecendo antes de sairem do ninho o que, ao nosso ver, devese ao nosso não conhecimento do material de que os pais se utilizam, na natureza, para a nutrição dos filhos.

\section{4 - Coryphospingus cucullatus rubescens (Swainson) (Emberizinae)}

Para êste belo Fringilídeo, a nomenclatura popular reservou os nomes "tico-tico rei", "sangrinho" ou "foguinho", a última das quais recordando a tonalidade vermelha escarlate do topete dos machos adultos.

- Pássaro de nutrição mista, .pois, embora se adapte a uma alimentação exclusivamente granívora, constitui excelente devorador de insetos, fazendo-nos acreditar que tal seja a sua principal fonte de nutrição na natureza.

Observamos a nidificação de um casal. O ninho foi construido no interior de um pequeno compartimento de paredes fechadas por arames. Dois ovos, sôbre os quais existem as referências de IHERING (1900) e EULER (1900).

$\mathrm{O}$ período de incubação anda ao redor de 13 dias.

\section{SUMMARY}

A short contribution to the Natural History of some Brazilian Frigillidae

The following species of Brazilian Fringillidae are mentioned here, the first of which being more deeply studied: 
1 -Oryzoborus angolensis angolensis (Linnaeus).

2 -Oryzoborus crassirostris maximiliani Cabanis.

3 -Cyanocompsa cyanea sterea Oberholser.

4 -Coryphospingus cucullatus rubescens (Swainson).

About each one of the referred species, the Author gives native names, some datas and observations on its reproduction and behaviour under captivity, as well as on its natural alimentation.

Some considerations about the geographical races of Oryzoborus angolensis: O. a. angolensis (Linnaeus) and O. a. torridus (Scopoli) -are also made.

Both the races occur in Brasil and, according to the Author's opinion, they are not satisfactorily caracterized.

\section{LITERATURA CITADA}

ANÔNIMO, 1941 - Lisia sistematica de las Aves Argentinas elaborada por la Seccion Ornitologica del Museo Argentino de Ciencias Naturales, Buenos Aires. El Hornero 8 (1): 137-153.

BRITO, Pedro de M., 1950 - Ninhos e ovos de algumas Aves Brasileiras e dados sôbre a reprodução em cativeiro. Rev. Brasil. Biol. 10 (3) : 315-331, 2 figs.

EULER, Carlos, 1900 -Descripção de ninhos e ovos das Aves do Brasil. Rev. Mus. Pau. 4: 9-148, 3 tabs.

FRIEDMANN, Herbert, 1948 - Birds collected by the National Gecgraphic Society's Expeditions to Northern Brazil and Southern Venezuela. Proc. of the U. S. Nat. Mus. 97: 373-570, est. 16-27.

GYLDENSTOLPE, Nils, 1945 - The bird fauna of Rio Juruá in Western Brazil. Kungl. Svenska Vetenskapsakademiens Handlingar 22 (3): 1-338, Stockholm.

HELLMAYR, Charles E., 1906 - On the birds of the Island of Trinidad. Nov. Zool. 13: 1-60.

1908 - An account of the birds collected by Mons. G. A. Baer in the State of Goiaz, Brazil.Nov. Zool. 15: 13102.

XI. Ploceidae - Catalogue of birds of the Americas, part Mus. of Nat. History, zool. series, 13 (11): 1-662. 
HEMPEL, Adolph, 1949 - Estudo da alimentação natural de Aves silvestres do Brasil. Arq. Inst. Biol. 19: 237-268, 5 tabs.

IHERING, H. von, 1900 - Catalogo critico-comparativo dos ninhos e ovos das aves do Brasil. Rev. Mus. Pau. 4: 191-300, 25 figs.

IHERING, Hermann von \& Rodolpho von Ihering, 1907 - Catalogos da Fauna Brazileira, Vol. I - As Aves do Brazil, pág. $1-485,2$ ests.

LOEFGREN, A. \& H. L. Everett, 1905 - Analysis de Plantas - Ensaio para uma Botanica Descriptiva das especies mais frequentes em São Paulo e outros Estados do Brasil. São Paulo.

LORDELLO, Luiz Gonzaga E., 1950 - Albinismo em Fringillidae. Rev. de Agric. (Piracicaba) 25 (3-4): 115-120, 4 figs.

- , 1950 - Insetos para as Aves - Sôbre o Tenebrio molitor Linnaeus, Sit. e Faz. (S. Paulo) 16 (2) : 7-9, 3 figs.

- 1951 - Passer domesticus albino e considerações acêrca de algumas anomalias de plumagem verificadas em Aves do Brasil. Entregue para publicação em Dusenia ( $P u$ blicatio Periodica de Scientia Naturali).

MONTE, Oscar, 1928 - Notas ornithologicas. Cha. e Qui. (S. Paulo) 37 (2):: 163-165.

OLIVEIRA PINTO, Oliverio M. de, 1935 - Aves da Bahia. Rev. Mus. Pau. 19: 1-325.

OLIVERIO PINTO, 1940 - Aves de Pernambuco. Arq. de Zool. do Est. de S. Paulo 1 (5) : 219-282, 6 ests.

OLIVEIRA PINTO, Olivério Mário de, 1944 - Catálogo das Aves do Brasil, 2̇a. Parte. Publ. esp. do Dep. de Zool. de S. Paulo, pág. I-XI + 1-700, il.

SANTOS, Eurico, 1940 - Em Pássaros do Brasil - Vida e costumes, 2a. ed., F. Briguiet \& Cia., pág. 1-277, fig. 1-60, Rio de Janeiro.

TORRES, A. Di Paravicini, 1947 - Em Melhoramentos dos Rebanhos, Edit. Cia. Melhoramentos, pág. 1-243, il., São Paulo.

VIEIRA, Carlos Octaviano da C., 1936 - Nomes vulgares de Aves do Brasil. Rev. Mus. Pau. 20: 437-489. 


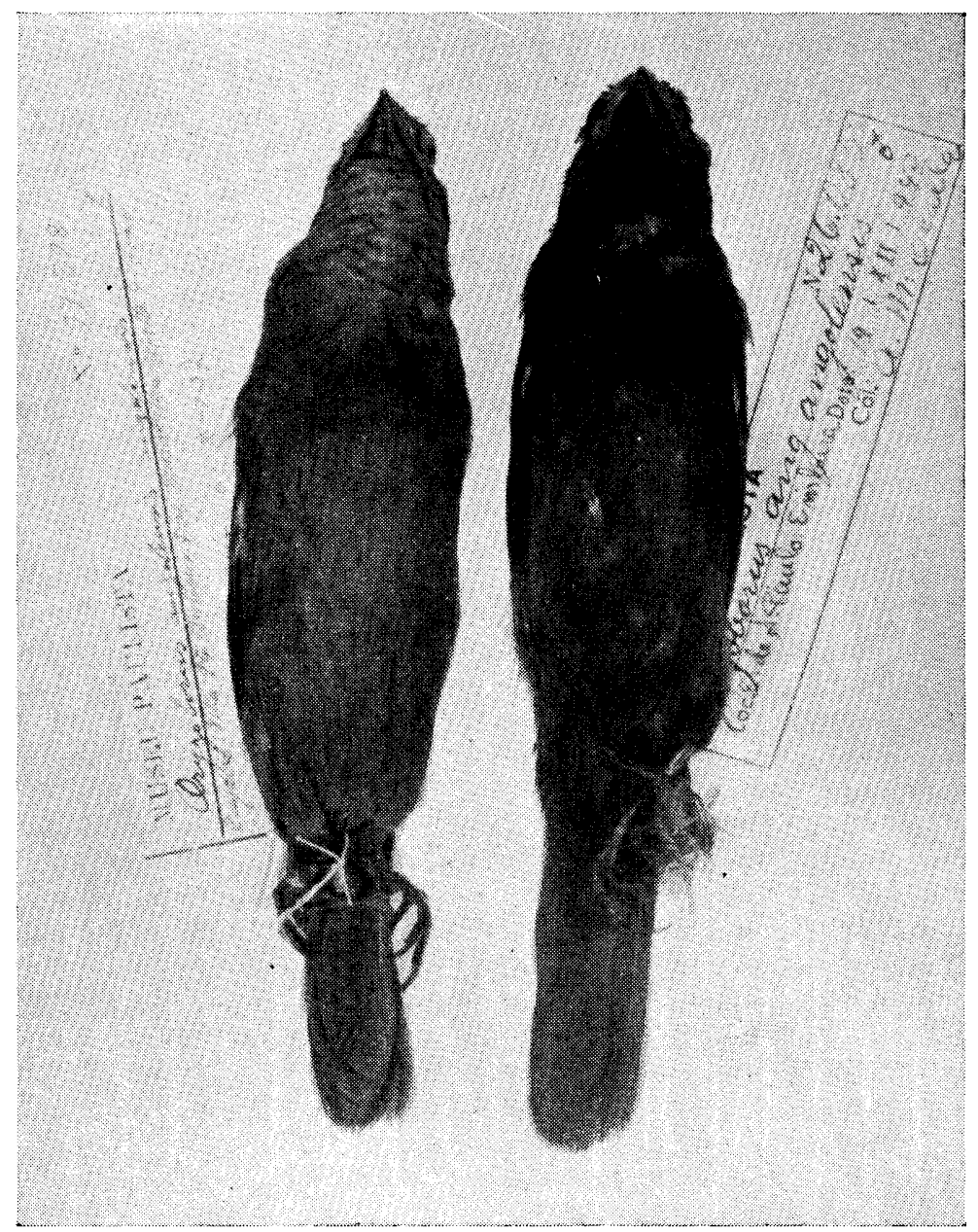

Est. I - Oryzoborus angolensis angolensis (Linnaeus) Macho á direita 


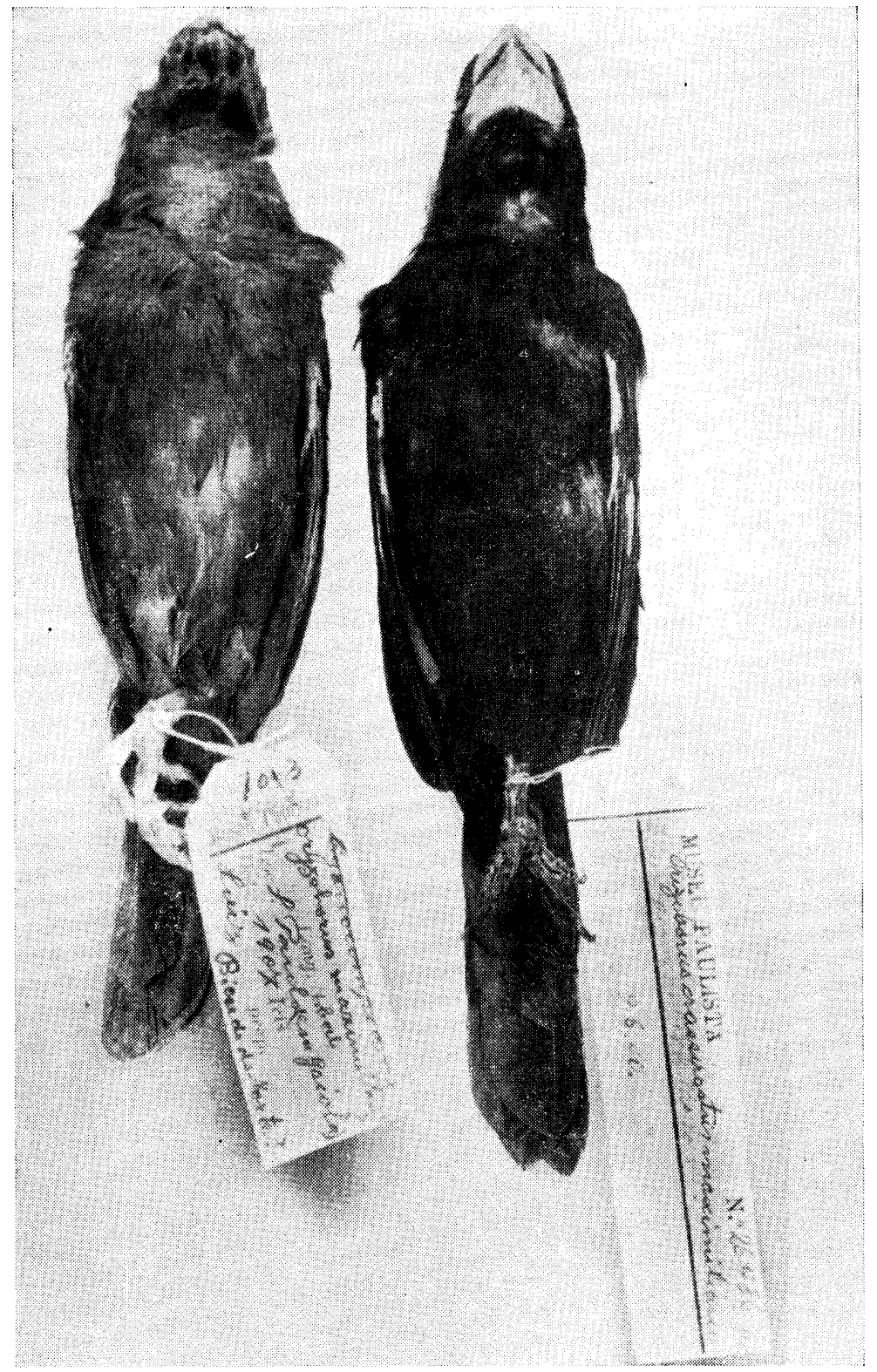

Est. II Oryzoborus crassirostris maximiliani Cabanis Macho á direita 


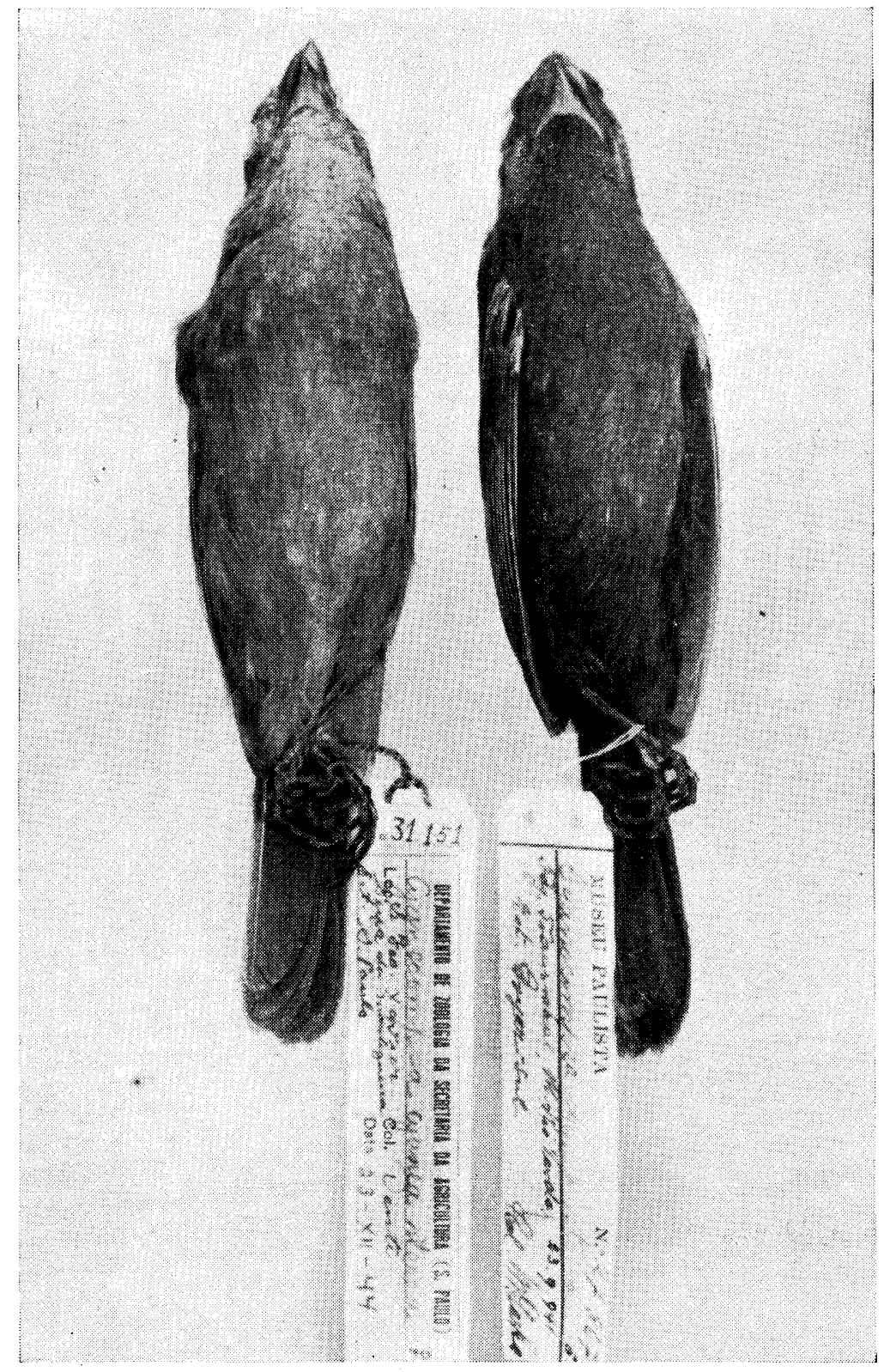

Est. III Cyanocompsa cyanea sterea Oberholser Macho á direita 


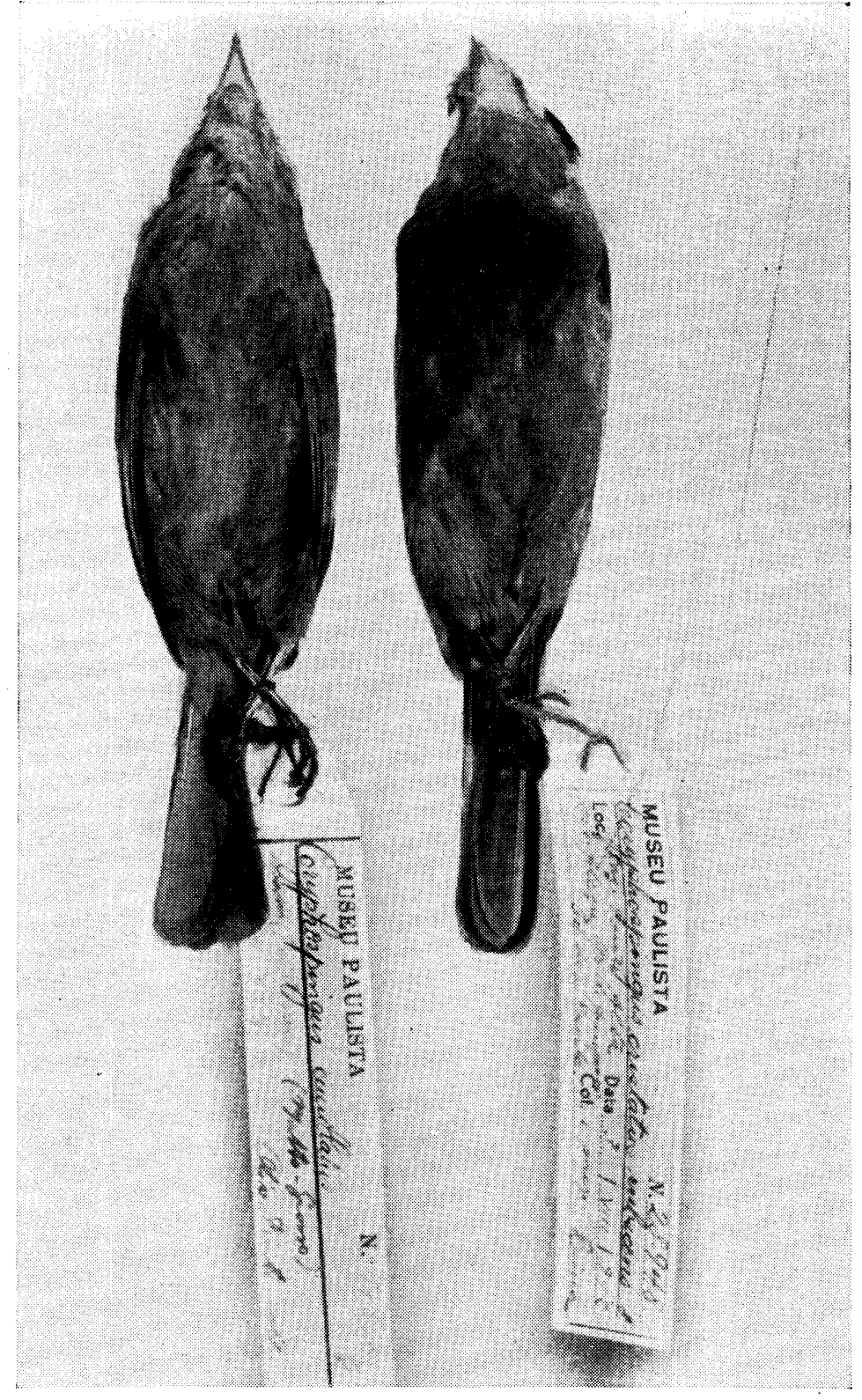

Est. IV - Coryphospingus cucullatus rubescens (Swainson) Macho á direita 